\title{
A escrita entre mundos de Najat El Hachmi: gênero, política e pertencimento
}

\author{
Luciane Alves ${ }^{1}$ \\ Gerson Neumann ${ }^{2}$
}

\begin{abstract}
Resumen: Los Estudios Literarios han posibilitado importantes discusiones sobre la relación entre migración y género. Distintas autoras contemporáneas trabajan el tema en sus obras, además de que, en algunos casos, hayan vivido personalmente la experiencia del desplazamiento. En este trabajo destacamos la presencia de la escritora catalana de origen marroquí Najat El Hachmi, que presenta en sus obras principalmente la situación de las mujeres migrantes de origen árabe en España. Buscamos hacer un panorama de los principales temas trabajados por la autora en sus textos, con especial atención a la novela La filla estrangera (2015), además de su situación como sujeto en el medio político en el cual se encuentra.
\end{abstract}

Palabras clave: Najat El Hachmi; migración; género; pertenecimiento.

Resumo: O campo dos Estudos Literários tem possibilitado importantes discussões a respeito das relações entre migração e gênero. Diversas autoras contemporâneas abordam a temática em suas obras, além de em alguns casos viverem pessoalmente a experiência do deslocamento. Neste trabalho destacamos a presença da escritora catalã de origem marroquina Najat El Hachmi, que aborda em suas obras principalmente a situação das mulheres migrantes de origem árabe na Espanha. Procuramos fazer um panorama dos principais temas abordados pela autora em seus textos, com especial atenção ao romance La filla estrangera (2015), assim como sua inserção enquanto sujeito no meio político no qual se encontra.

Palavras-chave: Najat El Hachmi; migração; gênero; pertencimento.

Introdução

A migração é, sem dúvida, o grande tema da atualidade, debatido e pesquisado nos mais diferentes campos do saber. Com isso, não estamos afirmando que se trate de um movimento novo, não existente anteriormente; pelo contrário, o ser humano é nômade desde os primórdiois de sua existência e a migração de um local para outro à procura de melhores condições de vida faz parte de seu ser. Nos últimos anos, no entanto, o deslocamento de pessoas vem passando por um interessante processo de feminização. Conforme os dados apontados pelo Observatório de Migrações de Portugal, ${ }^{3}$ é possível

1 Doutoranda do PPGLET-UFRGS (Estudos Literários - Teoria, Crítica e Comparatismo) com o projeto "Mulheres migrantes na literatura contemporânea".

2 Prof. Dr. do Instituto de Letras da UFRGS - Departamento de Línguas Modernas/Setor de Alemão.

3 A Newsletter de março de 2017 do Observatório de Migrações de Portugal mostra que devido aos impactos da globalização e à demanda por determinados serviços aumentou consideravelmente o número de mulheres que se deslocaram ao país. A instituição também disponibiliza um gráfico de fluxo migratório que mostra 
perceber o aumento do número de mulheres que empreendem o movimento migratório, sozinhas ou com a família, diferente de épocas anteriores em que, de maneira geral, acompanhavam maridos ou familiares que haviam iniciado a campanha migratória.

Este dado é um marco social importante, considerando que grande parte das mulheres migrantes provêm de meios culturais conservadores, onde às mulheres ainda está relegado um lugar opressivo, de subjugação e silenciamento. Todo aquele que se desloca, de maneira física ou simbólica, rompe fronteiras, o que de modo geral está associado a perdas, conflitos e experiências traumáticas. No caso das mulheres, diante de sociedades ainda profundamente patriarcais, não será o deslocamento uma necessidade inerente e obrigatória para "ser"?

Se pensamos no silenciamento relegado pelo discurso colonial aos sujeitos subalternos, como aponta Gayatri Spivak, o sujeito feminino é ainda mais oprimido, por já ser o outro em qualquer sistema patriarcal, "o sujeito subalterno não tem história e não pode falar, o sujeito subalterno feminino está ainda mais profundamente na obscuridade" (2012, p. 85). Neste caso, o deslocamento, físico ou simbólico, ocasiona um rompimento na estrutura tradicional, subverte a ordem e abre a possibilidade da fala, o reconhecimento enquanto sujeito.

O campo dos Estudos Literários tem possibilitado importantes discussões sobre as relações entre migração e gênero. Ao observarmos as publicações literárias contemporâneas, podemos perceber o crescente número de escritoras mulheres que vivenciam a experiência do deslocamento e/ou criam personagens migrantes em seus textos ficcionais. Personagens que em sua maioria são protagonistas e contam a própria história, têm voz.

No Brasil há também exemplos de escritoras envolvidas na temática em questão, destacando-se as autoras Paloma Vidal, migrante argentina no Brasil, e Adriana Lisboa, carioca que reside e trabalha nos Estados Unidos. Em contexto mundial é bastante lembrada a escritora nigeriana Chimamanda Ngozi Adichie, cuja obra Americanah, é uma importante referência ao tema das mulheres migrantes. E embora ainda pouco conhecida no Brasil, é muito citado na Europa o nome de Najat El Hachmi, escritora catalã de origem marroquina que foca em suas narrativas a situação das mulheres migrantes de origem árabe. Neste trabalho destacaremos a apresentação de sua obra e os elementos que a relacionam com os temas expostos nesta introdução.

\section{Najat El Hachmi}

Najat El Hachmi nasceu na cidade de Nador, no Marrocos, e migrou aos oito anos com a mãe para Vich, interior da comunidade autônoma da Catalunha, na Espanha, para onde seu pai já havia migrado antes de ela nascer. Essa situação era comum na época, quando diversos trabalhadores se deslocaram do Marrocos à Catalunha em busca de melhores condições financeiras para mais tarde buscar suas famílias.

O primeiro livro da autora, o ensaio Jo també soc catalana, foi publicado em 2004 e nele já aparecem os temas que posteriormente serão desenvolvidos em seus textos ficcionais. No ensaio citado, Najat El Hachmi parte de aspectos biográficos para abordar

que, apesar de um ápice nos anos de 2008 e 2009 e uma queda em 2013, o fluxo de mulheres em relação aos homens continua sendo maior na atualidade. 
o tema da migração na região da Catalunha e, principalmente, reivindicar seu espaço de pertencimento e denunciar o lugar de "eterno estrangeiro" delegado aos imigrantes.

Foi a partir da publicação do primeiro livro de ficção, L'últim patriarca, de 2008, que a escritora começou a receber destaque na mídia espanhola, conquistou prêmios e elogios da crítica. L'últim patriarca recebeu o prêmio Ramon Llull, o mais importante das letras catalãs, o que é bastante significativo ao considerarmos que se trata de uma autora migrante em uma região marcada pelo nacionalismo separatista e em um país onde o racismo sofrido pelos sujeitos de origem árabe se mantém muito forte. Nesse caso, Najat El Hachmi figura claramente como agente político engajado de forma múltipla: a mulher migrante que deixa sua terra, com a família, sendo mulher em um sistema familiar de tradição religiosa muçulmana, fixando-se em uma região na Espanha que se destaca pela sua forte marcação identitária em relação ao restante do país.

Além do grande valor literário de seus textos, o que já seria motivo suficiente para seu reconhecimento no meio editorial, destacamos o contexto em que se insere a autora por reconhecermos que a formação de um cânone e a escolha pela publicação de determinadas obras, em grande parte da historiografia literária, levou mais em conta os valores políticos de autores e temas que a qualidade dos textos, principalmente quando se trata de autorias femininas e de sujeitos inseridos culturalmente fora do eixo europeu/ocidental.

No contexto espanhol, especificamente, é preciso lembrar que a tensão entre árabes e espanhóis remonta há muitos séculos. A região que hoje compõe politicamente a Espanha foi ocupada por árabes durante sete séculos (entre 711 e 1492), e somente em 1492, com a conquista de Granada, última região de Al-Ándalus, os reis católicos conseguiram a unificação do território. A presença árabe na cultura, nas artes e até mesmo no idioma espanhol ainda é bastante perceptível e na mesma intensidade se manteve o discurso de rechaço e preconceito.

Além do racismo sofrido pela origem étnica, a predominância do machismo nos meios culturais aos quais nos referimos e a força de grupos contrários aos processos de migração de sujeitos africanos aos países europeus são elementos que tornam ainda mais emblemático o reconhecimento da escrita e a presença de Najat El Hachmi. E esse movimento não se restringe à literatura da autora marroquina, outras autoras migrantes também passam a ser "visíveis" no meio literário. É possível perceber uma enorme força política nestes textos, marcados pela presença da temática migrante. Novos nomes ocupam o cânone contemporâneo e simbolizam uma ruptura com os modelos tradicionais (autores homens, brancos, europeus, etc), estabelecendo claramente uma situação de contato que causa tensão, ainda que comum em contextos de tal tipo. Em meio a esse cenário, a autora Najat El Hachmi desenvolve a sua escrita.

Outro dado importante na trajetória de Najat El Hachmi é o fato de seu nome figurar na recente coletânea Women Writers in Catalan, obra-catálogo que pretende apresentar ao público anglófono as 50 principais autoras catalãs contemporâneas, além de dez autoras clássicas. Toda a obra de El Hachmi foi originalmente publicada em catalão, e a própria escritora comentou em entrevistas que seria impossível fazê-lo diferente, pois esse é o idioma em que pensa, sente e se expressa melhor.

Embora suas obras não sejam biográficas, apresentam, sem dúvida, elementos de sua vivência enquanto mulher migrante, principalmente no que se refere à visão estereotipada com que são vistos os estrangeiros/imigrantes nos países ocidentais. Em seus romances, a autora mostra de maneira aprofundada os elementos que citamos anteriormente: a 
situação das mulheres na sociedade de origem árabe, e sua condição como migrantes na Espanha, o racismo e a discriminação sofridos na cultura de chegada devido à origem étnica, e a opressão do fundamentalismo religioso da cultura de origem.

\section{A vida entre dois mundos}

Em Jo també soc catalana (2004), Najat El Hachmi define sua escrita como um pensamento fronteiriço, cuja função é entender duas realidades diferentes. O propósito desta escrita seria a busca da felicidade entre dois mundos, uma forma de encontrar liberdade em meio às fronteiras e à falta de pertencimento. Este tema é aprofundado no romance La filla estrangera 4 de 2015, onde a protagonista se vê dividida entre a cultura materna e os elementos de uma cultura nova, da qual não se sente pertencente. Najat El Hachmi percebe o contexto que cerca o ser migrante em todas as suas categorias e formas e tenta levá-lo ao mundo através do texto.

Narrada em primeira pessoa, a obra conta a história de uma jovem marroquina que migrou com a mãe para o interior da Catalunha em busca do pai que as abandonou. Não sabemos seu nome, o que marca um aspecto importante da falta de identificações da personagem. De certa forma, o enredo nos leva a perceber que ela, em nível subjetivo, não sabe quem é, dividida entre duas culturas, nas quais não encontra elementos sólidos de identificação.

Dos 18 para os 19 anos, a protagonista anônima se vê forçada a escolher entre seguir os costumes de sua cultura de origem ou procurar novos caminhos na Espanha. Ao aceitar casar-se com o primo marroquino, que mal conhece, suas perspectivas individuais são sufocadas em uma tentativa de aliviar o sofrimento e as preocupações que marcam a existência de sua progenitora.

A figura da mãe é um elemento muito importante na elaboração do sentimento de pertencimento. Ela é a personificação da origem, das raízes e da cultura natal, e não se integra à cultura do novo país. A própria autora aponta para o fato de que, em um contexto migrante, o machismo e o excesso de apego aos valores tradicionais são maiores. Segundo Najat El Hachmi, isto ocorre porque a mulher passa a ser o símbolo da manutenção dos valores e da cultura, ou seja, é uma marca do pertencimento ao grupo de origem, principalmente por não existir confiança no entorno do novo local de residência ${ }^{5}$.

A protagonista do romance, ao contrário da mãe, não se identifica com o meio cultural de origem, ainda que não encontre aceitação na cultura do país de residência. Ao voltar ao Marrocos, não o reconhece como um lugar seu, passando a percebê-lo como espaço da terra e da língua da mãe. Por outro lado, cada passo em direção à sua incorporação ao meio cultural em que vive simboliza o afastamento da mãe, o que a preocupa e a faz recuar, mantendo-se, também por escolha, em um espaço de não pertencimento cultural pleno. Essa característica, no entanto, é inerente ao ser migrante, não apenas a alguém que migra de um país a outro, mas também em contextos de migrações internas, regionais.

A falta de identificações com o território natal ocasiona um excessivo apego à figura

4 Optamos pela tradução espanhola de Rosa Maria Prats: La hija estrangera.

5 Entrevista publicada no jornal El periódico, em 02/09/2015, sob o título "Najat El Hachmi: 'No renunciaré a mi origen como escritora'." 
materna como uma espécie de ilusão de unidade e pertencimento a uma origem. Cada costume tradicional não adquirido pela filha reforça sua ideia de deslocamento e de afastamento da mãe, sentimento também proporcionado pela incorporação de elementos do novo local, como comentado anteriormente.

Durante uma festa com mulheres da família, um som feito com a língua, muito típico da cultura, permite a reflexão sobre o não-lugar em que se encontra a protagonista:

$Y$ alli, quieta como un pasmarote ante mi propio reflejo, me sentí repentinamente forastera, incapaz de pertenecer al mismo grupo que mi madre aunque lo intentara y tratase de aprender. He aqui como un chasquido puede hacerte sentir desarraigada. (EL HACHMI, 2015, p. 121)

Recuperando os estudos de identidade de Stuart Hall e suas próprias vivências enquanto sujeito, cuja obra tornou-se referência para os estudos das experiências de pessoas que vivem fora do seu espaço original, vemos que a situação vivida pela personagem se assemelha à experiência do teórico que foi migrante e estrangeiro na Inglaterra e nunca se sentiu totalmente identificado com o contexto social jamaicano, ao qual pertencia originalmente.

A recusa e o distanciamento dos modelos culturais ocasionou um afastamento maior de sua família e também de seu país. Com o processo de migração, Stuart Hall se encontrou uma vez mais confrontado com a necessidade de renegociação da identidade. Não se identificava mais com os padrões sociais jamaicanos, mas sabia que jamais seria um inglês. Somente com a "nova Jamaica", que emergiu nos anos 70, pós-colonial, pósescravocrata, Hall se sentiu à vontade para refletir de forma mais significativa sobre a situação de seu país de origem.

Mas essa Jamaica não era a mesma de sua infância, que se deu no final da era colonial, o que o levou a "negociá-la como um "estrangeiro familiar"” (2008, p 115). A respeito da Inglaterra, Hall comenta que se sentiu na mesma posição em que se encontrava diante da "nova Jamaica":

Paradoxalmente, eu tinha a mesma relação com a Inglaterra. Tendo sido preparado pela educação colonial, eu conhecia a Inglaterra de dentro. Mas não sou nem nunca serei um inglês. Conheço intimamente os dois lugares, mas não pertenço completamente a nenhum deles. (HALL, 2008, p. 415).

O lugar híbrido do sujeito migrante é simbolizado desde o início do romance La filla estrangera através da linguagem. A importância da tradução é destacada em diversas passagens em que a protagonista se debate entre a "língua do seu pensamento", que não é nomeada ${ }^{6}$ e a língua da mãe, o rifenho. Idioma sem possibilidade de tradução, uma língua que "vuela por el aire y ha quedado fijada unicamente en la piel de las mujeres" (2015, p. 97).

De repente, este desajuste léxico, tan insignificante, tan banal, me ha hecho recordar cuán lejos estoy de ella, de su mundo, de su manera de ver y entender las cosas. Por más que tra-

6 Segundo Najat El Hachmi, o fato de não mencionar a língua como catalão (idioma em que é escrito originalmente o romance) se deve ao caráter extremamente político que isto implica no contexto espanhol, com as discussões sobre a separação da região, tema que ela não pretendia discutir neste texto. 
duzca, por más que intente verter las palabras de una lengua a otra, nunca lo conseguiré, siempre habrá diferencias. Pese a ello, traducir continúa siendo una distracción dulce, una forma tangible al menos, de desear llevar a cabo este acercamiento de nuestras realidades, que me ha sido útil desde que vinimos aqui. (EL HACHMI, 2015, p. 18)

Nessa passagem de El Hachmi, pode-se estabelecer um diálogo com a obra de Homi Bhabha, mantendo ainda o diálogo com Hall. Ao nos concentrarmos na importância dada ao ato de traduzir elementos da cultura, estamos observando como se dá o contato do migrante, tomando como exemplo elementos da obra em questão, com a nova cultura, com a qual passa a travar contato. No livro O local da cultura, Bhabha traz uma reflexão sobre como o novo entra no mundo através da tradução.

A cultura migrante do "entre-lugar", a posição minoritária, dramatiza a atividade da intraduzibilidade da cultura; ao fazê-lo, ela desloca a questão da apropriação da cultura para além do sonho do assimilacionista, ou do pesadelo do racista, de uma "transmissão total do todo", em direção a um encontro com o processo ambivalente de cisão e hibridização que marca a identificação com a diferença da cultura. (BHABHA, 2007, p. 308) ${ }^{7}$

O desajuste léxico simboliza outros desajustes: culturais, de pertencimento, de geração, etc. A consciência do não-lugar ocupado por ela leva a um sentimento de frustração e incapacidade de ser compreendida. Sua expressão de linguagem não é a da suposta origem e está longe de ser a do local onde se encontra. A identidade fronteiriça, que marca inclusive o espaço íntimo, mostra a solidão provinda da falta de pertencimento:

Solo con alguien que fuese como yo, alguien que también tuviera una madre como la mía y hubiese aprendido esta lengua que nos es extranjera y la hubiera interiorizado, como yo, hasta el punto de que se hubiera convertido en la lengua principal de sus pensamientos, solo con alguien asi podría hablar como yo me hablo a veces, mezclando las dos lenguas. (EL HACHMI, 2015, p. 25-26)

A obra propicia a visão dos elementos culturais como um conflito na vivência cotidiana e íntima da personagem, que, ao decidir inicialmente seguir a tradição familiar, casando-se com o primo, se sente constrangida e com medo de ser mal vista ou perder seu emprego, já que muitas vezes havia escutado comentários preconceituosos sobre outras mulheres árabes que passaram pela mesma experiência, vivendo na Espanha. Nesta situação, torna-se evidente o lugar que cabe à sua cultura dentro do cenário europeu, no qual ela é "apenas mais uma marroquina". A exclusão do árabe, o racismo, a falta de melhores oportunidades, assim como a frequente marcação da estranheza, mostram que, apesar do tempo, não ocorre uma verdadeira incorporação do imigrante ao meio cultural:

Aunque, bien pensado, en esta ciudad es poco probable que una marroqui pase desapercibida, porque su sola presencia, con la cabeza cubierta y los ropajes largos, ya llama la atención de quienes han vivido aqui toda la vida y no entienden esta repentina presencia de forasteros. (EL HACHMI, 2015, p.140)

7 Cabe ressaltar que Homi K. Bhabha, na passagem citada acima, estabelece claro diálogo com Walter Benjamin, na obra Illuminationen. 
Além disso, a narrativa ressalta a questão geracional, a diferença entre os que migram adultos e os que vão com a família ainda na infância e adolescência, pois os últimos, apesar do racismo e das dificuldades, têm melhores oportunidades de aprender outro idioma e expressar-se na fronteira entre duas culturas, algo que é negado, principalmente, às mulheres mais velhas, cuja barreira idiomática as coloca em um lugar ainda mais marginalizado, como exiladas no meio cultural. Não existe acolhimento aos sujeitos que supostamente não se adaptam à cultura de chegada. A aparente adaptação não passa de uma domesticação, na qual é sugerido um trabalho árduo para perda dos elementos de origem. Como aponta Eric Landowski em Presenças do outro (2002):

Assimilador, o grupo dominante não rejeita ninguém, e se pretende ao contrário, por princípio, generoso, acolhedor, aberto para o que vem de fora. Porém, ao mesmo tempo, toda diferença de comportamento um pouco marcada, pela qual o estrangeiro trai sua proveniência, parece, para ele, extravagância despida de razão. (LANDOWSKI, 2002, p. 6)

A escritora e ativista egípcia Nawal El Saadawi, em diversas entrevistas e textos, como A face oculta de Eva, publicado originalmente em 1977, aponta para a ideia de que nenhuma das sociedades religiosas, seja ocidental ou oriental, dará espaço de liberdade plena às mulheres. Os mecanismos de opressão e silenciamento, simbolizados, por exemplo, pelo uso do véu, não se originam nas culturas muçulmanas, como o discurso ocidental pretende mostrar. Segundo a autora egípcia, estes elementos são anteriores a esta cultura e já tinham o mesmo significado na tradição judaico-cristã.

No caso de La fila estrangera, há uma discussão interessante neste sentido, pois a personagem questiona as diferentes posições relacionadas ao uso do véu. Ao negar-se a usar o véu, aponta para o fato de que ela já faz parte de uma cultura diferente e que seu uso não deveria mudar a imagem que sua família tem dela, não deveria torná-la uma pessoa diferente. Por outro lado, ao decidir usá-lo para agradar a mãe, que chega a ponto de adoecer devido à preocupação com a rebeldia da filha, a protagonista se torna mais consciente de sua não incorporação ao meio social europeu, pois se identifica com a colega de trabalho que foi demitida ao passar a usá-lo. Neste sentido, o não uso do adereço é igualmente uma marca de opressão por parte da sociedade europeia, pois simboliza o racismo e a intolerância em relação a uma cultura diferente.

O curta-metragem Hijab, dirigido por Xavi Sala, rodado em 2005, apresenta esta mesma questão. No filme, conhecemos o dilema da jovem Fatma, que, ao chegar a um colégio para seu primeiro dia de aulas, é coagida por uma supervisora escolar a retirar seu $h_{i j a b^{8}}$, antes de entrar na sala de aula. Os argumentos da mulher para convencer a menina giram em torno da necessidade de igualdade entre os estudantes e o quanto o adereço usado pela menina destoaria dos demais discentes. Fatma, constrangida, acaba cedendo à imposição da supervisora, embora afirme que se sente melhor usando o véu.

Ao entrar na sala de aula, a protagonista do filme se depara com um número enorme de colegas utilizando algum tipo de adereço, como bonés, chapéus, etc, que diferenciam uns dos outros. A expressão confusa da menina, que encerra a narrativa fílmica, simboliza fortemente a situação em que se encontram os sujeitos que sofrem este tipo de preconceito, dissimulado por um suposto discurso igualitário.

8 Véu de uso generalizado no mundo muçulmano que cobre o cabelo e o colo, mas não oculta o rosto. 
Para a protagonista de La fila estrangera, tais conflitos, percebidos pela personagem nos dois contextos em que está inserida, passam a atormentá-la de tal modo que a levam ao nível da loucura. Ao perceber que em ambos os meios culturais existe opressão e exclusão, ela passa a não ver saída e sucumbe a um ataque nervoso após recorrer a antidepressivos na esperança de aplacar um impasse impossível de ser resolvido. Sua decisão final pela fuga e a mudança a uma cidade grande (cuja descrição nos leva a entender que é Barcelona) não simbolizam um "final feliz", pois o contexto social não parece apresentar saídas reais para o drama da personagem. Não ocorre o encontro com a "felicidade entre dois mundos".

Nos principais caminhos sugeridos pela narrativa existem ainda a ausência de afeto e de acolhimento, faltando elementos que sugiram a real incorporação deste sujeito, que até o final da obra segue em busca de lugares de aceitação. O rompimento com a mãe poderia sinalizar o primeiro passo de encontro com um espaço próprio; no entanto, ao abandonar também o filho que tem depois de algum tempo casada, como forma de consolo para a solidão da mãe, a personagem parece mostrar que de qualquer modo sua liberdade precisou ser financiada com uma parte de si mesma.

\section{A escrita como espaço de ruptura}

A escrita no caderno, que sempre levava consigo, parece ser o único lugar onde a protagonista de La filla estrangeira pode revelar-se como um sujeito completo, com todas as suas contradições e seus conflitos, sem o julgamento e a ambivalência de sua vida social. A escrita se torna o lugar mais genuíno do eu, o espaço de pertencimento não encontrado no meio externo. $\mathrm{O}$ ato de escrever pode ser pensado simbolicamente como o "rompimento do véu", pois, ainda que se trate de um texto íntimo, descobre-se ao final que essas anotações formam justamente a narrativa que estamos lendo. $\mathrm{O}$ texto subverte o silenciamento até então designado a este sujeito que não encontrava caminhos para expressar-se.

A obra Orientalismo, de Edward Said (2007), apresenta uma reflexão importante para esta discussão. Ao pensarmos na análise que o autor palestino faz da obra de Flaubert, é possível perceber o silenciamento das mulheres pelo patriarcado e a importância da recuperação do lugar de fala pela escrita de mulheres migrantes, um espaço não somente negado pelo homem branco, mas também pelo homem da cultura de origem. A possibilidade de expressão aparece justamente em um espaço fronteiriço, em um lugar outro, que é a escrita, e que procura romper com os padrões discursivos binários e excludentes.

$\mathrm{Na}$ introdução da coletânea Tendências e Impasses, Heloísa Buarque de Hollanda já apontava para o fato de que Said, em Orientalismo, "ao examinar a forma como são constituídos, na perspectiva ocidental, os discursos e as interpretações sobre o Oriente, reconhece explicitamente que está lidando com questões idênticas àquelas propostas pelas tendências atuais dos estudos feministas." (1994, p. 8). O principal ponto destacado pela autora em sua leitura da obra de Said é o fato de que

os estudos feministas, assim como os estudos étnicos e antiimperialistas, promovem um deslocamento radical de perspectiva ao assumirem como ponto de partida de suas análises o direito de grupos marginalizados de falar e representar-se nos domínios politicos e intelectuais que normalmente os excluem, usurpam suas funções de significado e representação e falseiam suas realidades históricas. (HOLLANDA, 1994, p. 8) 
Quando Flaubert descreve uma realidade "tipicamente oriental" através da figura da cortesã egípcia, ele traz um homem branco europeu que fala por ela e é negado à mulher "oriental" o direito de autoexpressão: "Ele era estrangeiro, relativamente rico, do sexo masculino, e esses eram fatos históricos de dominação que lhe permitiram não apenas possuir fisicamente Kuchuk Hanem, mas falar por ela e contar a seus leitores de que maneira ela era "tipicamente oriental"' (SAID, 2007, p. 33).

Podemos pensar que este espaço é recuperado na escrita contemporânea que, como vimos na introdução, apresenta grande número de personagens mulheres protagonistas e/ ou narradoras de suas histórias. Estas narradoras/protagonistas muitas vezes também são porta-vozes das histórias de outras mulheres que ganham importância nas narrativas. Ao trazer estas outras histórias, as obras apresentam maior número de modelos identitários que acabam por romper com as descrições estereotipadas das mulheres figuradas nas narrativas de voz masculina e presente em grande parte da historiografia literária.

\section{Escrita migrante: o movimento e a movimentação dos espaços literários}

O teórico e comparatista alemão Ottmar Ette apresenta em seu ensaio "Migração" (2015) a ideia de um espaço desfronteirizante, que define diferentes posicionamentos possíveis em um contexto cultural e literário migrante. Quando analisa a escrita de José $\mathrm{F}$. A. Oliver, Ette identifica nesta escrita elementos semelhantes aos que podemos encontrar na obra de Najat El Hachmi, especialmente quando consideramos o reconhecimento dado a sua obra. Segundo Ette:

a oscilação entre estrangeiro e próximo, entre língua (estrangeira) e territorialidade (próxima) torna-se um processo inconcluso, desequilibrado e com isso ao mesmo tempo desfronteirizado, no qual o estrangeiro não é consumido pelo próprio, não é suprimido, mas elevado como um tesouro. (ETTE, 2015, p. 253)

A tentativa de rompimento com as oposições binárias oriente/ocidente, nas quais o discurso do orientalismo coloca o primeiro como opressor e bárbaro e o segundo como libertador e civilizado, pode ser analisada na escrita da autora como um espaço desfronteirizante entre estas culturas, marcado por uma escrita que questiona estes modelos. Partindo de outra ideia de Ottamr Ette, desenvolvida em Literatura en movimiento (2008), podemos considerar a escrita de Najat El Hachmi como um tipo de escrita em movimento. De acordo com o teórico, este termo se refere a textos literários "que desacatam o subvierten las fronteiras establecidas" (2008, p. 67), uma dinâmica de escrita que ultrapassa fronteiras em diversos níveis e contextos e que "debe representar a través de su própia dinámica un mundo en movimiento" (2008, p. 67).

A escrita migrante de mulheres, principalmente no caso da autora apresentada, pode ser subversiva tanto pela formação identitária da personagem protagonista como pelo espaço em movimento (e movimentador dos) nos cânones que se estabelecem. Trata-se de uma escrita intercultural e duplamente deslocada que, ao cruzar fronteiras físicas e culturais, também cruza os limites designados aos papéis de gênero e ao lugar de fala.

Esta mesma problemática pode ser relacionada ao lugar da literatura migrante nos sistemas literários, principal tema desenvolvido nos estudos de Ottmar Ette. A partir das ideias de desfronteirização e de escrita em movimento, é possível perceber a complexidade 
deste tipo de texto em cenários culturais ainda marcados por fronteiras discursivas muito fortes e também as contribuições das escritas migrantes a um processo de rearticulação dos cânones nacionais. Para Ette, a escrita migrante não está fora das literaturas nacionais, faz parte dos sistemas literários tanto nacionais como mundiais, ocupando um lugar móvel dentro deles, que permite que estas categorias sejam repensadas e expandidas.

A literatura de migração não é um anexo ou um apêndice, mas sim uma parte integrante da literatura de um dado local, de um país ou de uma região, que se diferencia funcionalmente - e não apenas tematicamente - mas que não pode ser excluída como uma categoria separada e, com isso, descartada (Ibid, p. 248). O autor questiona as classificações "literatura estrangeira" ou "literatura de migração" e aponta o perigo de que apenas se tolere o outro, mas não se respeite ou incorpore a diferença, marcando a outridade como forma de proteção do próprio. Ette defende que o espaço nacional seja "reespacializado" em um contexto de movimento que permita uma visão de literatura vetorizada, capaz de estabelecer novas ligações por meio de movimentos migratórios em diferentes planos, transportando conhecimentos transculturais que se relacionam com as condições do cenário geopolítico e cultural, num desdobrar de escritas e narrativas específicas e dinâmicas.

Uma literatura vetorizada não é, porém, ilimitada, e tampouco é ilimitado o respectivo campo literário ligado a ela, o qual ainda é prioritariamente conduzido pelas instituições nacionalmente operantes. Com a crise e a dissolução dos espaços nacionais e nacionalculturais supostamente homogêneos, multiplicam-se ainda mais as fronteiras. Elas, porém não são mais vistas como inatingíveis ou, no melhor dos casos, ultrapassadas na consciência de uma identidade 'própria' e estável, mas sim marcadas em sua diversidade (Ibid, p. 248).

No entanto, é importante que se considere que esta vetorização apontada por Ette tem como ponto de partida a Europa e sua relação com outras culturas. A marcação do lugar de fala é necessária para que de fato exista a inserção de outras vozes nos discursos literários e permita pensar em outros pontos de partida destes discursos e caminhos de vetorização da literatura. Ao considerarmos que Najat El Hachmi tem suas origens no Marrocos, a inversão de perspectiva torna possível pensar de que forma os discursos e as narrativas literárias africanas, e principalmente a escrita de mulheres, se vetorizam em direção à Europa, dialogando com outras formações discursivas e culturais e que mudanças e perspectivas isso pode gerar nos sistemas literários aos quais pertencem ou se aproximam.

\section{Considerações finais}

A obra da escritora Najat El Hachmi nos leva a refletir, portanto, sobre a problemática da migração de mulheres no cenário contemporâneo e a produção literária das mesmas nesse espaço muitas vezes indefinido. Sua narrativa é crítica e questionadora, apesar de seu caráter artístico-ficcional, tornando sua obra conhecida no meio em que escreve. E não somente, visto que sua obra é citada na publicação em língua inglesa sobre as 50 escritoras catalãs.

A migração de pessoas de um espaço para outro em busca de melhores condições de vida e a tematização desse movimento nas diferentes expressões artísticas não é um tema novo. Há muito tempo o ser humano migra. Contudo, as narrativas construídas em consequência de tais deslocamentos de pessoas, como o vemos atualmente no Norte da África para a Europa, por exemplo, trazem em si elementos novos que marcarão esse processo. E no caso da obra de Najat El Hachmi, tem-se em especial a escrita da 
mulher, apresentando personagens protagonistas também mulheres envolvidas com a problemática feminina em meio ao movimento migratório.

A produção artística de Najat El Hachmi apresenta aspectos singulares, constrói uma narrativa de caráter estético-crítico que ultrapassa categorias e conceitos determinados por disciplinas e ou linguagens específicas, confrontando questões sociais, políticas, religiosas, linguísticas e, especialmente, de gênero, na sua obra. Tem-se, portanto, em El Hachmi, uma clara reflexão crítica sobre a literatura contemporânea, que apresenta como pano de fundo o contexto migratório da mulher norte-africana, especificamente do Marrocos, para a Espanha, para a Comunidade Autônoma da Catalunha.

Em diálogo com a obra de El Hachmi, procurou-se estabelecer, acima, um diálogo com a obra teórica de Ottmar Ette, o qual traz à discussão o "saber-sobreviver" da literatura, como ciência da vida. A obra de Najat El Hachmi é a sua vida falando, sobrevivendo, por meio da arte, por meio da Literatura. E conforme Ette, um dos teóricos que fundamentam a nossa argumentação, a função da literatura - assim como da filologia - é tornar audível o que há muito se acreditava perdido (ETTE, 2005, p. 59), é permiter que outras vozes tenham o seu espaço.

Cabe mencionar aqui que Ette escreveu uma trilogia sobre o saber sobre-viver, sendo que dois desses volumes já estão acessíveis em tradução para o português: Zwischenweltenschreiben. Literaturen ohne festen Wohnsitz, em português EscreverEntreMundos. Literaturas sem morada fixa, Überlebenwissen. Die Aufgabe der Philologie, em português SaberSobreViver. A (o)missão da filologia e o ainda não traduzido ZusammenLebensWissen. List, Last und Lust literarischer Konvivenz im globalen Maßstab, em tradução livre seria: SaberViverJunto. Artimanha, Fardo e Prazer da convivência literária em escala global.

Portanto, poder trazer a obra de Najat El Hachmi ao público leitor e atento à crítica literária, e ter mais informações sobre a autora migrante que escreve na Catalunha, região que se encontra em profundas discussões sobre pertencimento político a um poder central espanhol, é objetivo nesse momento. A obra de Najat El Hachmi encontra-se nesse cenário politicamente tenso. Além disso, sua obra traz à discussão justamente a "vida entre dois mundos", abordando os problemas que enfrenta uma mulher migrante que se desloca do Marrocos para a Espanha e lá pretende iniciar uma vida. A escrita, nessa caso, dá-se como a apresentação de "um estado de ruptura", nesse espaço de tensão, onde se movimentam os migrantes, como abordamos no último ponto, "Escrita migrante: o movimento e a movimentação dos espaços literários.” É justamente nesses espaços de fricção (termo empregado por Ette), ou espaços de tensão, que ocorrem as transformações e as revoluções, é nesses espaços que se busca sobreviver (por meio da literatura).

Najat El Hachmi é estrangeira na Catalunha e possivelmente sempre o será e sua luta por reconhecimento constante, pois para aquele que se sente catalão, por talvez estar naquele espaço político há mais tempo, ela permanecerá identificada como uma marroquina ou mesmo uma africana. $\mathrm{O}$ pertencimento à comunidade de origem, por sua vez, também se enfraquece, pois ela perdeu muitas caraterísticas ao envolver-se em um meio cultural distinto. Superficialmente a escritora pode ser apresentada nesse cenário do chamado espaço entre, mas esse espaço não existe, pois ela está em um lugar que é o dela e este é um lugar, um espaço. Estamos lidando com a experiência de uma pessoa, cuja vida se assemelha a de grupos (migrantes, refugiados, minoritários, etc.) - não de caso individual; e, ainda que fosse, deveria ser observado - e neste contexto a literatura de El Hachmi é a voz de sua sobre-vivência. 


\section{Referências}

BHABHA, H. O local da cultura. Belo Horizonte: Editora UFMG, 2007. Trad. Myriam àvila, Eliana Lourenço de L. Reis, Gláucia Renate Gonçalves.

CHEN, K-H. A formação de um intelectual diaspórico: uma entrevista com Stuart Hall. In: SOVIK, L. (Org.) Da diáspora. Identidades e mediações culturais. Belo Horizonte: UFMG/UNESCO, 2003, p. 407-433.

EL HACHMI, N. La hija extranjera. Barcelona: Planeta, 2015. Trad. Rosa María Prats. EL SAADAWI, N. La cara oculta de Eva [Recurso digital]. Madrid: Kailas Editorial, 2017.

ETTE, O. EscreverEntreMundos. Literarturas sem morada fixa. Curitiba: UFPR, 2018. Trad. Rosani Umbach, Dionei Mathias, Teruco Arimoto Spengler.

. Literatura en movimiento. Madrid: Consejo Superior de Investigaciones

Científicas, 2008. Trad. (esp.) Rosa Maria S. de Maihold.

. Sabersobreviver: a (o)missão da filologia. Rosani. Curitiba: UFPR, 2015. Trad.

Paulo Soethe e Rosani Umbach.

. ZusammenLebensWissen. List, Last und Lust literarischer Konvivenz im globalen Maßstab. Berlin: Kadmos Verlag, 2010.

HALL, S. Da diáspora. Identidades e mediações culturais. Belo Horizonte: UFMG/ UNESCO, 2003.

HOLLANDA, H. B. de. (Org). Tendências e impasses - o feminismo como crítica da cultura. Rio de Janeiro: Rocco, 1994.

SAID, E. W. Orientalismo: o Oriente como invenção do Ocidente. São Paulo:

Companhia das Letras, 2007. Trad. de Rosaura Eichenberg.

SPIVAK, G. C. Pode o subalterno falar?. Belo Horizonte: Editora UFMG, 2010.

Recebido em: 13/08/2018 Aceito em: 11/09/2018 